\title{
Modulation of some biochemical complications arising from alloxan- induced diabetic conditions in rats treated with Senna occidentalis leaf extract
}

\author{
Ojochenemi Ejeh Yakubu ${ }^{1 *}$, Okwesili Fred Chiletugo Nwodo ${ }^{2}$, Chinedu Imo ${ }^{1}$, Sylvester Michael Chukwukadibia Udeh², \\ Mikailu Abdulrahaman ${ }^{3}$, Maryval Ogaku Ogri ${ }^{4}$ \\ ${ }^{1}$ Department of Biochemistry, Federal University Wukari, Nigeria. \\ ${ }^{2}$ Department of Biochemistry, University of Nigeria, Nsukka, Nigeria. \\ ${ }^{3}$ Department of Microbiology, Kogi State University, Anyigba Nigeria. \\ ${ }^{4}$ Department of Medical Biochemistry, Cross River University of Technology, Calabar, Nigeria.
}

\author{
ARTICLE INFO \\ Article history: \\ Received on: $28 / 12 / 2015$ \\ Revised on: 25/01/2016 \\ Accepted on: 03/03/2016 \\ Available online: 26/08/2016 \\ Key words: \\ Senna occidentalis, \\ biochemical complications, \\ alloxan-induced diabetes.
}

\begin{abstract}
The present study was designed to evaluate the effects of Senna occidentalis in alloxan-induced diabetic and its complications in Wistar rats. Thirty male Wistar rats with body weight ranging from 180-250 g were selected for the study. Diabetes was induced by single intraperitoneal dose of alloxan injection $(150 \mathrm{mg} / \mathrm{kg}$ body weight). Treatment was carried out orally using aqueous and ethanol extracts of Senna occidentalis leaves at $100 \mathrm{mg} / \mathrm{kg}$ body weight once daily for 21-days. The fasting blood sugar (FBS), Thiobarbituric acid Reactive Substance (TBARS), alkaline Phosphatase (ALP), alanine aminotransferase (ALT), aspartate aminotransferase (AST), serum bilirubin and full blood count levels were evaluated. The result of the study showed decrease in FBS, TBARS, liver enzymes, bilirubin, platelets (PLT) and white blood count (WBC) as well as increase in lymphocytes (LYM) and red blood count (RBC). The result of study showed to a large extent the effects of Senna occidentalis in the management of some complications resulting from diabetes and its complications.
\end{abstract}

\section{INTRODUCTION}

Diabetes Mellitus is a complex disease with many complications. The causes of diabetes are many and its pathophysiology are multiple and would require more than a single therapeutic agent to reverse majority of its effect. Treatment in diabetes is aimed at achieving good control of blood glucose levels and preventing the development of secondary complications. Many pharmacological therapies have been used to improve the status of diabetes by several mechanisms such as, inhibition of carbohydrate metabolizing enzymes, manipulation of glucose transporters, $\beta$-cell regeneration and enhancing the insulin releasing activity $[1,2]$.At present, drug therapies either alone or in combination cannot restore blood glucose homeostasis and many limitations exist in their use. The management of diabetes without any side effect is still a challenge to the medical system.

\footnotetext{
* Corresponding Author

Email:oj4real_2007@yahoo.co.uk
}

Many efforts have been made to identify new hypoglycaemic agents obtained from different sources especially medicinal plants because of their effectiveness, fewer side effects and relatively low cost. Several medicinal plants have been investigated for their beneficial use in different types of diabetes in the traditional medicine even though their biologically active compounds and efficacy are unknown $[3,4]$. Senna occidentalis is a Eudicots flowering plant of the Fabaceae family. It is native to the tropical and subtropical regions of America. The common names are coffee weed, Stinking-weed or mogdad coffee in English. In Hindi it is called Badikanodi, Chakunda or Kasonda, In Hausa, it is known as Tapasa. The leaves and pods (shells) are usually administered in the Ayurvedic and Unani systems of medicine as infusion, and considered a great tonic. The plant is used to cure sore eyes, haematuria, rheumatism, typhoid, asthma and disorders of haemoglobin, it is also reported to cure leprosy [5]. A decoction of the plant is used in hysteria, in dysentery and other stomach troubles, and also as an application to sores, itch and inflammation of the rectum [6]. The plant is employed in dropsy, and as a vermifuge. Along with other plants as, it is made into an ointment used for skin diseases. 


\section{MATERIALS AND METHODS}

\subsection{Collection and preparation of plant materials}

Fresh leaves of Senna occidentalis were collected from its natural habitat in Okuku, Yala L.G.A, Cross River State, Nigeria. It was authenticated in the Department of Biological Sciences, Cross River University of Technology Calabar. The leaves were dried under shade at room temperature and pulverized using mortar and pestle followed by an electric blender.

\subsection{Extraction}

About 500g of finely ground powder of Senna occidentalis was weighed into a plastic rubber and filled with $2500 \mathrm{mlof}$ ethanol $(1: 5 \mathrm{w} / \mathrm{v})$ and was allowed to stand for $24 \mathrm{hrs}$ at room temperature, was filtered using Wattman no. 1 filter paper, then the filtrate was concentrated under reducing pressure using rotary evaporator with a vacuum pump. The concentrated extract was weighed. Same procedure was repeated for aqueous extraction substituting ethanol with distilled water.

\subsection{Animal management}

Male albino rats were purchased from the animal house of the Department of Medical Biochemistry, Cross River University of Technology, Calabar Nigeria. They were acclimatized for two weeks prior to the commencement of the experiment, kept at a room temperature, and feed using broiler starter. They were weighed prior to the experiment.

\subsection{Induction of Diabetes}

Diabetes was induced by subjecting the animals to overnight fasting, followed by intraperitoneal injection of alloxan with a single dose of $150 \mathrm{mg} / \mathrm{kg}$ body weight. Alloxan is capable of inducing hyperglycermia as a result of massive pancreative insulin release, after $72 \mathrm{hrs}$ the animal were tested and confirmed to be diabeteic. Animals with FBS 200mg/dl and above were selected for the study. The blood glucose concentrations of the animals were determined weekly using a glucometer (Accu-Check Active).

\subsection{Experimental Design}

Thirty (30) male albino rats were divided into five groups consisting of six animals each. Out of the five groups four groups were made diabetic as described below.

Group 1: Normal Control (Non diabetic, no treatment).

Group 2: Diabetic control (Diabetic, no treatment).

Group 3: Diabetic + Senna occidentalis aqueous extract $100 \mathrm{mg} / \mathrm{kg}$

Group 4: Diabetic + Senna occidentalis ethanolic extract $100 \mathrm{mg} / \mathrm{kg}$

Group 5: Diabetic + Glibenclamide

Treatment was made orally for 21 days.

\subsection{Sample Collection and Processing}

At the end of administration, the animals fasted overnight, they were weighed using a standard weighing balance, anaesthetized under chloroform anaesthesia and quickly brought for sacrifice. Blood samples were collected through cardiac puncture. The organs (kidney and liver) were surgically removed, weighed and immediately rinsed with ice cold normal saline and kept in the refrigerator prior to analysis. Blood sample of about 3 $4 \mathrm{mls}$ was collected via cardiac puncture and separated into a plane tube and heparinized tube for chemistry and haematological analysis. The sample for chemistry analysis was centrifuged using a standard centrifuge at the speed of $3500 \mathrm{rpm}$ for 10 minutes in order to obtain serum from whole blood.

\subsection{Fasting Blood Glucose (FBG) Determination}

FBG was determined as described by Ibrahim \& Rizk [7]. One drop of rat blood through the tail was collected on a glucose assay strip and read using Accu-Check Active glucometer. This was carried out on a weekly basis for 21 days.

\subsection{Determination of Thiobarbituric Acid Reactive Substance (TBARS)}

This was carried out according to the method described by Frode and Medeiros [8]. $10 \mathrm{~g}$ (10\%) of TCA and $0.67 \mathrm{~g}(0.67$ $\%)$ TBA was weighed and dissolved in to $100 \mathrm{ml}$ of distilled water for use. About $100 \mu \mathrm{l}$ of tissue homogenate was added into a test tube containing $2 \mathrm{ml}$ of TCA. $2 \mathrm{ml}$ of TBA was added and mixed thoroughly. It was incubated at $80^{\circ} \mathrm{C}$ for 30 minutes in water bath and cooled immediately under ice. The sample mixture was then centrifuged at 3,500rpm for 10 minutes and the absorbance was read immediately at $535 \mathrm{~mm}$ using a UV/VIS spectrophotometer.

\subsection{Aspartate aminotransferase (AST)}

Aspartate aminotransferase (AST) catalyzes the transamination of aspartate to alpha-ketoglutarate to form glutamate and oxaloacetate, which then reacts with 2,4-dinitrophenylhydrazine to form hydrazone derivative of oxaloacetate, a coloured complex which can be measured at $546 \mathrm{~nm}$. Aspartate aminotransferase was determined as described by Reitman and Frankel [9] using assay kits (Agape Laboratories Ltd, UK).

\subsection{Alanine aminotransferase (ALT)}

Alanine aminotransferase (ALT) catalyzes the transamination of alanine to alpha-ketoglutarate to form glutamate and pyruvic acid, which then reacts with 2,4-dinitrophenylhydrazine to form hydrazone derivative of pyruvate, a coloured complex which can be measured at $546 \mathrm{~nm}$. Alanine aminotransferase was determined as described by Reitman and Frankel [9] using assay kits (Agape Laboratories Ltd, UK).

\subsection{Alkaline phosphatase (ALP)}

Serum alkaline phosphatase was determined as described by Klein et al. [10]. Serum alkaline phosphatase catalyses the hydrolysis of a colourless substrate of phenolphthalein monophosphate giving rise to phosphoric acid and phenolphthalein which, at alkaline $\mathrm{pH}$ values turns into a pink colour that can be determined photo-metrically at $550 \mathrm{~nm}$. 


\subsection{Serum bilirubin}

This was determined colorimetrically according to the method described by Jendrassic and Grof [11], using assay kits (Agape Laboratories Ltd, UK). Conjugated bilirubin reacts with diazotized sulphanilic acid in alkaline medium to form a blue complex. Total bilirubin is determined in the presence of caffeine, which releases albumin bound bilirubin, by the reaction with diazotized sulphanilic acid.

\subsection{Determination of Haematological Parameters.}

The total Red blood cell count (RBC) lymphocyte concentration (LYM), White blood cell count (WBC) and Platelet count were determined using Abacus 280 auto haematology analyzer.

\section{RESULTS AND DISCUSSION}

\subsection{Fasting Blood Sugar (FBS)}

Alloxanization of normal rats led to significant increase $(\mathrm{p}<0.05)$ in FBS as shown in group 2-5 (table 1) compared to normal rats in group 1 . There was significant decrease $(\mathrm{p}<0.05)$ in FBS level across the weeks (wk 1>wk2>wk3) in group 3-5 treated with aqueous and ethanol extracts as well as glibenclamide. No statistical significance $(\mathrm{p}<0.05)$ was observed between the effects exhibited by the extract and glibenclamide at week 3 .

\subsection{Liver and kidneys Thiobarbituric Acid Reactive Substances (TBARS) Levels}

Significant increase $(p<0.05)$ was observed in the TBARS levels of the diabetic control group compared to normal control (table 2). Treatment of diabetic animals with the extracts and glibenclamide caused significant decrease $(p<0.05)$ in TBARS concentration in both the liver and kidneys of diabetic control group.

\subsection{Serum liver enzyme activities}

There was significant increase $(\mathrm{p}<0.05)$ in liver enzyme (ALT, AST, ALP) activities owing to diabetic condition caused by alloxanization (table 3) compared to normal control group. Treatment of diabetic rats with aqueous and ethanol extracts caused significant decrease $(\mathrm{p}<0.05)$ in the enzyme activities compared to the diabetic control group. Glibenclamide treatment of diabetic rats also caused significant decrease $(p<0.05)$ in the enzyme activities compared with the diabetic control. However, the extracts elicited more effects than the glibenclamide treatment, though not statistically significant $(\mathrm{p}<0.05)$.

\subsection{Serum bilirubin concentration}

Treatment of diabetic rats with the extracts caused significant decrease $(\mathrm{p}<0.05)$ in serum bilirubin concentration compared with the diabetic control (table 4). The decrease in serum total bilirubin concentration caused by glibenclamide was not statistically significant $(\mathrm{p}<0.05)$ compared with the diabetic control.

\subsection{Full Blood Count: white blood count (WBC), lymphocyte (LYM), red blood count (RBC) and platelets (PLT).}

In the full blood count, diabetic condition caused significant increase $(\mathrm{p}<0.05)$ in WBC and PLT in group 2 (table 5) compared to the normal control in group 1. Treatment of diabetic rats with aqueous extract and glibenclamide in group 3 and 5 had no significant difference $(\mathrm{p}<0.05)$ from the diabetic control group, except the group treated with ethanol extract i.e for WBC, but PLT was significantly lower $(\mathrm{p}<0.05)$ in aqueous extract and glibenclamide. Unlike WBC, LYM and RBC levels were significantly lower $(\mathrm{p}<0.05)$ in diabetic control compared to the normal control. Hence treatment with extracts as well as glibenclamide caused significant increase in diabetic control in LYM and RBC levels compared to the diabetic control group.

Table 1: FBS levels in diabetic and normal rats treated with Senna occidentalis extracts and glibenclamide.

\begin{tabular}{|c|c|c|c|c|}
\hline \multirow[b]{2}{*}{ GROUP } & \multicolumn{3}{|c|}{ FASTING BLOOD SUGAR (FBS)mg/dl } & \multirow[b]{2}{*}{ WK 3} \\
\hline & DAY 0 & WK 1 & WK 2 & \\
\hline NORMAL CONTROL & $84.08 \pm 05.81^{\mathrm{a}}$ & $83.96 \pm 05.80^{\mathrm{a}}$ & $75.04 \pm 03.53^{\mathrm{a}}$ & $83.16 \pm 05.58^{\mathrm{a}}$ \\
\hline DIABETIC CONTROL & $217.84 \pm 06.15^{b}$ & $222.64 \pm 06.47^{\mathrm{c}}$ & $203.68 \pm 09.74^{\mathrm{c}}$ & $213.36 \pm 03.09^{c}$ \\
\hline DIABETIC +100g S.O AQ EXT & $222.48 \pm 02.47^{\mathrm{bc}}$ & $172.48 \pm 06.49^{\mathrm{b}}$ & $122.32 \pm 08.21^{\mathrm{b}}$ & $118.24 \pm 01.05^{\mathrm{b}}$ \\
\hline DIABETIC $+100 \mathrm{~g}$ S.O ETH EXT. & $244.48 \pm 08.32^{\mathrm{c}}$ & $170.24 \pm 09.93^{\mathrm{b}}$ & $102.16 \pm 05.54^{\mathrm{bc}}$ & $108.48 \pm 04.70^{\mathrm{b}}$ \\
\hline DIABETIC+GLIBENCLAMIDE & $203.84 \pm 05.90^{\mathrm{b}}$ & $186.24 \pm 02.69^{b}$ & $135.44 \pm 07.23^{\mathrm{c}}$ & $119.36 \pm 05.22^{b}$ \\
\hline
\end{tabular}

Values are mean \pm SD. All treated groups are compared with control.

Values with different superscript across the group are statistically significant at $\mathrm{p}<0.05$.

Table 2: Liver and kidneys TBARS levels in diabetic and normal rats treated with Senna occidentalis extracts and glibenclamide

\begin{tabular}{|c|c|c|}
\hline \multicolumn{3}{|c|}{ THIOBARBITURIC ACID REACTIVE SUBSTANCES (nmol/ml) } \\
\hline$\overline{\text { GROUP }}$ & TBARS L & TBARS K \\
\hline NORMAL CONTROL & $0.22 \pm 0.06^{\mathrm{a}}$ & $0.12 \pm 0.03^{\mathrm{a}}$ \\
\hline DIABETIC CONTROL & $0.34 \pm 0.07^{\mathrm{b}}$ & $0.27 \pm 0.08^{\mathrm{b}}$ \\
\hline DIABETIC + $100 \mathrm{~g}$ S.O AQ EXT & $0.23 \pm 0.02^{\mathrm{a}}$ & $0.12 \pm 0.02^{\mathrm{a}}$ \\
\hline DIABETIC $+100 \mathrm{~g}$ S.O ETH EXT. & $0.24 \pm 0.04^{\mathrm{a}}$ & $0.13 \pm 0.02^{\mathrm{a}}$ \\
\hline DIABETIC+ GLIBENCLAMIDE & $0.26 \pm 0.03^{\mathrm{a}}$ & $0.12 \pm 0.03^{\mathrm{a}}$ \\
\hline
\end{tabular}

Values are mean \pm SD. All treated groups are compared with control.

Values with different superscript across the group are statistically significant at $\mathrm{p}<0.05$. 
Table 3: Serum liver enzyme activities in diabetic and normal rats treated with Senna occidentalis leaf extracts and glibenclamide.

\begin{tabular}{|c|c|c|c|}
\hline \multicolumn{4}{|c|}{ LIVER ENZYMES ACTIVITY (IU/L) } \\
\hline GROUP & ALP & ALT & AST \\
\hline NORMAL CONTROL & $32.27 \pm 3.25^{\mathrm{a}}$ & $20.34 \pm 0.48^{\mathrm{a}}$ & $30.89 \pm 1.24^{\mathrm{a}}$ \\
\hline DIABETIC CONTROL & $54.12 \pm 4.99^{\mathrm{c}}$ & $61.10 \pm 1.55^{\mathrm{d}}$ & $50.41 \pm 0.57^{\mathrm{c}}$ \\
\hline DIABETIC $+100 \mathrm{~g}$ S.O AQ EXT & $34.78 \pm 5.86^{\mathrm{b}}$ & $31.06 \pm 1.35^{\mathrm{b}}$ & $31.75 \pm 2.53^{\mathrm{b}}$ \\
\hline DIABETIC $+100 \mathrm{~g}$ S.O ETH EXT. & $35.57 \pm 7.83^{\mathrm{b}}$ & $30.54 \pm 0.80^{\mathrm{b}}$ & $34.11 \pm 0.16^{\mathrm{b}}$ \\
\hline DIABETIC+ GLIBENCLAMIDE & $36.05 \pm 7.36^{\mathrm{b}}$ & $37.01 \pm 0.86^{\mathrm{c}}$ & $40.41 \pm 0.63^{\mathrm{bc}}$ \\
\hline
\end{tabular}

Values are mean \pm SD. All treated groups are compared with control.

Values with different superscript across the group are statistically significant at $\mathrm{p}<0.05$.

Table 4: Serum bilirubin concentration in diabetic and normal rats treated with Senna occidentalis leaf extracts and glibenclamide.

\begin{tabular}{lcc}
\hline GROUP & SERUM BILIRUBIN (mg/dI) & DIRECT BIL. \\
\hline NORMAL CONTROL & TOTAL BIL. & $0.21 \pm 0.01^{\mathrm{a}}$ \\
DIABETIC CONTROL & $0.52 \pm 0.03^{\mathrm{a}}$ & $0.71 \pm 0.02^{\mathrm{b}}$ \\
DIABETIC +100g S.O AQ EXT & $1.10 \pm 0.03^{\mathrm{b}}$ & $0.24 \pm 0.05^{\mathrm{a}}$ \\
DIABETIC +100g S.O ETH EXT. & $0.60 \pm 0.12^{\mathrm{a}}$ & $0.21 \pm 0.01^{\mathrm{a}}$ \\
DIABETIC+ GLIBENCLAMIDE & $0.51 \pm 0.13^{\mathrm{a}}$ & $0.30 \pm 0.08^{\mathrm{a}}$ \\
\hline VIC & $0.74 \pm 0.02^{\mathrm{ab}}$ & \\
\hline
\end{tabular}

Values are mean \pm SD. All treated groups are compared with control.

Values with different superscript across the group are statistically significant at $\mathrm{p}<0.05$.

Table 5: Full blood count in diabetic and normal rats treated with Senna occidentalis leaf extracts and glibenclamide.

\begin{tabular}{|c|c|c|c|c|}
\hline & \multicolumn{4}{|c|}{ FULL BLOOD COUNT } \\
\hline$\overline{\text { GROUP }}$ & WBC & LYM & RBC & PLT \\
\hline NORMAL CONTROL & $1.31 \pm 0.95^{\mathrm{a}}$ & $2.57 \pm 0.06^{\mathrm{b}}$ & $4.88 \pm 0.24^{\mathrm{b}}$ & $227.36 \pm 061.66^{\mathrm{b}}$ \\
\hline DIABETIC CONTROL & $3.58 \pm 0.64^{\mathrm{b}}$ & $0.54 \pm 0.09^{\mathrm{a}}$ & $1.41 \pm 0.60^{\mathrm{a}}$ & $295.44 \pm 04.99^{\mathrm{d}}$ \\
\hline DIABETIC +100g S.O AQ EXT & $2.17 \pm 0.92^{\mathrm{ab}}$ & $2.12 \pm 0.37^{\mathrm{b}}$ & $5.30 \pm 0.52^{\mathrm{b}}$ & $251.28 \pm 06.92^{\mathrm{c}}$ \\
\hline DIABETIC $+100 \mathrm{~g}$ S.O ETH EXT. & $1.81 \pm 0.14^{\mathrm{a}}$ & $3.40 \pm 0.56^{\mathrm{b}}$ & $3.96 \pm 0.94^{\mathrm{b}}$ & $284.00 \pm 65.25^{\mathrm{cd}}$ \\
\hline DIABETIC+ GLIBENCLAMIDE & $2.30 \pm 0.64^{\mathrm{ab}}$ & $2.88 \pm 0.04^{\mathrm{b}}$ & $3.97 \pm 0.25^{\mathrm{b}}$ & $184.64 \pm 19.09^{\mathrm{a}}$ \\
\hline
\end{tabular}

Values are mean \pm SD. All treated groups are compared with control.

Values with different superscript across the group are statistically significant at $\mathrm{p}<0.05$.

Table 6: Packed Cell Volume (PCV) and haemoglobin ( $\mathrm{Hb})$ concentrations in diabetic and normal rats treated with Senna occidentalis leaf extracts and glibenclamide.

\begin{tabular}{lcc}
\hline & PACKED CELL VOLUME AND HAEMOGLOBIN & PCV $(\boldsymbol{\%})$ \\
\hline GROUP & HB $(\mathbf{g} / \mathbf{1 0 0 m l})$ & $47.86 \pm 10.99^{\mathrm{b}}$ \\
NORMAL CONTROL & $15.44 \pm 2.03^{\mathrm{b}}$ & $35.67 \pm 01.29^{\mathrm{a}}$ \\
DIABETIC CONTROL & $11.41 \pm 5.94^{\mathrm{a}}$ & $47.23 \pm 02.65^{\mathrm{b}}$ \\
DIABETIC +100g S.O AQ EXT & $15.09 \pm 3.77^{\mathrm{b}}$ & $47.44 \pm 02.21^{\mathrm{b}}$ \\
DIABETIC +100g S.O ETH EXT. & $16.62 \pm 8.51^{\mathrm{b}}$ & $1.7 .77 \pm 2.36^{\mathrm{b}}$ \\
DIABETIC+ GLIBENCLAMIDE & $14.83 \pm 01.13^{\mathrm{b}}$ & 46. \\
\hline
\end{tabular}

Values are mean \pm SD. All treated groups are compared with control.

Values with different superscript across the group are statistically significant at $\mathrm{p}<0.05$.

\subsection{Packed Cell Volume (PCV) and haemoglobin (Hb) concentrations}

PCVand Hb levels were significantly lower $(\mathrm{p}<0.05)$ in diabetic control compared to the normal control (table 6). Hence treatment with extracts as well as glibenclamide caused significant increase in diabetic control in PCV and $\mathrm{Hb}$ levels compared to the diabetic control group.

\section{DISCUSSION}

Diabetes is currently considered as a vascular disease [10]. It has also been considered by researchers that hyperglycaemia-induced oxidative stress is a critical pathogenic mechanism that initiates a plethora of cascade metabolic and vascular perturbations [11, 12]. Studies have revealed the beneficial effects of some secondary plant metabolites that possess antioxi-dant activity in diabetes management. Lipid peroxidation was investigated in our study by assessing the hepatic levels of TBARS; a significant increase in TBARS levels of diabetic rats was observed when compared to normal control rats. Numerous studies with human and animal models have also shown increased lipid peroxidative status in membranes of different tissues in diabetes $[13,14,15]$. The extract produced significant decreases in TBARS levels in treated diabetic rats when compared to diabetic control rats. Treatment with glibenclamide also caused a slight decrease in TBARS levels of the treated rats. These reductions could lead to a decrease in oxidative stress and hence a reductions in the rate of progression of diabetic complications in the liver.

Table 3 represents the changes in the activities of aspartate transaminase, alanine transaminase and alkaline phosphatase. In the assessment of liver damage by the determination of enzyme, enzyme levels such as aspartate transaminase and alanine transaminase are largely used. Elevated levels of serum enzymes are indicative of cellular leakage and loss 
of functional integrity of cell membrane in liver [16]. Hepatocellular necrosis leads to high level of serum markers in the blood, among these, aspartate transminase, alanine transaminase represents $90 \%$ of total enzyme and high level of alanine transminase in the blood is a better index of liver injury, but the elevated levels of enzymes are decreased to normal levels after treatment with the extract. Alkaline phosphatase concentration is related to the functioning of hepatocytes, high level of alkaline phosphatase in the blood serum is related to the increased synthesis of it by cells lining bile canaliculi usually in response to cholestasis and increased biliary pressure [17]. Increased level was obtained owing to alloxan administration and it was brought to normal level by the extract treatment. Treatment with $S$. occidentalis aqueous and methanol leaf extract decreased the serum levels of aspartate transaminase, alanine transaminase and alkaline phosphatase towards the respective normal value; that is an indication of stabilization of plasma membrane as well as repair of hepatic tissue damage caused by alloxan. The aforementioned changes can be considered as an expression of the functional improvement of hepatocytes, which may be caused by an accelerated regeneration of parenchymal cells.

Hyperbilirubinaemia was observed due to excessive haeme destruction and blockage of biliary tract. As a result of blockage of the biliary tract, there was mass inhibition of the conjugation reaction and release of unconjugated bilirubin from damaged and dead hepatocytes; this is in line with the report given by [18]. Administration of extract decreased the level of bilirubin, suggesting that it offered protection.

Haematological and biochemical indices have been reported to be a reliable parameter for assessment of the health status of animals. There was significant decrease $(p<0.005)$ in the level of RBC of the healthy rats and the treated rats compared to the untreated animals (Table 5).

These may be as a result of anaemia or the onset of glycosylation process in the untreated diabetic rats. Anaemia has been identified as a common complication of chronic kidney disease (CKD), affecting over half of all patients, and the most common cause of $\mathrm{CKD}$ in about $2 / 3$ of cases is diabetes mellitus [19]. There was a significant reduction $(\mathrm{P}<0.05)$ in WBC levels of diabetic rats treated with ethanolic leaf extract of Senna occidentalis compared to the untreated animals and those treated with aqueous leaf extract.

However, there was significant elevations in platelets levels of group treated with ethanolic extract and slight increase in lymphocytes levels of those treated with aqueous extract compared to the other groups. Ethanolic leaf extract of Senna occidentalis treatment may not have adverse effects on the bone marrow, kidney and heamoglobin metabolism, since it has been reported that only substances which significantly affect the values of red blood cells and associated parameters would have effects on the bone marrow, kidney and heamoglobin metabolism [20]. The results obtained from this study showed clearly that Ethanolic leaf extract of Senna occidentalis does possess hematopoietic activity and is not hematotoxic. The antihyperglycemic effect of the extracts was compared with glibenclamide, a standard hypoglycemic drug. Glibenclamide has long been used to treat diabetes, to stimulate insulin secretion from the pancreatic $\beta$-cells. From the results, it appears that still insulin producing $\beta$-cells are functioning in alloxan treated diabetic rats and stimulation of insulin release could be responsible for most of the observed metabolic activities. Further, the observed blood glucose-lowering effect in fasted normal and alloxan induced diabetic rats could possibly be due to the increased peripheral glucose utilization. A number of other plants have also been shown to exert hypoglycemic activity through stimulation of insulin release [21]. Our observations are in well agreement with the reports by several workers that alloxan-induced diabetes mellitus and insulin deficiency leads to increased blood glucose.

\section{CONCLUSION}

The chemical constituents of the various plants containing carbohydrates, phenolics, flavonoids, alkaloids, saponins and glycosides gives recovery of islet which gives increase in the pancreatic secretion of insulin from islet of Langerhans. The possible mechanism by which Senna occidentalis leaf extracts bring about its hypoglycaemic action may be by potentiating the insulin effect by increasing either the pancreatic secretion of insulin from cells of islets of Langerhans or its release from the bound form.

\section{REFERENCES}

1. Haffner SM, Alexander CM,Cook JJ. Scandinavian Simvastatin Survival Study Group. Reduced Coronary events in simvastatintreated patients with coronary heart disease and diabetes or impaired fasting glucose levels, sub group analysis from simvastatin survival study. Arch intern Me.1999; 159: 2661-2677.

2. Goldberg RB, Melllies MJ, Sacks FM. Cardiovascular events and their reduction with Pravastatin in diabetic and glucose intolerant myocardial infarction. Survivors with average cholesterol levels: Sub group analysis in the cholesterol and recurrent events. Care investigators. 1998; 98: 2513-2519.

3. Lyons JJ, Jenkins AJ, Zheng D, Lackland DT, McGee D, Gavey WT. Diabetic retinopathy and serum lipoprotein subclasses in DCCT/EDIC Cohort. Invest Opthalmol Vis Sci. 2004; 45(3): 910-918.

4. Tesfaye S, Chaturvedi N, Eaton SE, Ward JD, Manes C, IonescuTirgoviste G, Witte DR, Fuller JH. Vascular risk factors and diabetic neuropathy.N Engl J. Med. 2005; 352(18):1925-1927.

5. McGill HC, McMahan CA, Zieske AW, Sloop GD, Walcott JV, Troxclair DA. Associations of coronary heart disease risk factors with the intermediate lesion of atherosclerosisin youth. The Pathobiological Determinants of Atherosclerosis in Youth (PDAY) Research Group.ArteriosclerThromVasc Biol. 2000;20: 1998-2004.

6. Li TY, Hu FB, Colditz GA, Willet WC, Manson JE. Television watching and other sedentary behaviours in relation to risk of obesity and type 2 diabetes mellitus in women.JAMA.2003; 298(14):17851791.

7. Ibrahim SS, Rizk SM. Nicotinamide: a cytoprotectant against streptozotocin-induced diabetic damage in wistar rat brains. Afr. J. Biochem. Res. 2008;2(8):174-180.

8. Sharma SB, Hasir A, Prabhu KM, Murthy PS, Dez G. Hypoglycemic and hypolipidemic effect of ethanolic extract of seeds of Eugenia jambolona in alloxan- induced diabetic rabbits. J Ethnopharmacol. 2003; 85:201-640. 
9. Jendrassik L, Gróf P.Vereinfachtephotometrische Methodenzur Bestimmung des Blutbilirubins. Biochem Zeitschrift; 1938; 297:82-9.

10. Feillet-Coudray C, Rock E, Coudray C, Grzelkowska K, AzaisBraesco V, Dardevet D. Lipid peroxidation and anti-oxidant status in experimental diabetes. Clin.Chim.Acta.1999; 284:31-43.

11. Kakkar R, Mantha SV, Radhi J, Prasad K, Kalra J. Antioxidant defence system in diabetic kidney: A time course study. Life Sci.1997;60:667-679.

12. Aydin A, Orhan HA., Sayal M,Ozata G, Isumer A. Oxidative Stress and Nitric Oxide Related Parameters in Type II Diabetes mellitus: Effects of Glycaemic Control. Clin.Biochem.2001;34:65-70.

13. Obresova IG, Fathalah L, Lui E,Nourooz-Zadeh J. Early oxidative stress in diabetic kidney: effect of DL- $\alpha$-lipoic acid. Free Radic. Biol. Med. 2003;34:186-195.

14. Ugochukwu NH, Babady NE, CobourneMK, Gasset SR. The Effect of GongronemalatifoliumExtracts on Serum Lipid Profile and Oxidative Stress in Hepatocytes of Diabetic Rats. J. Biosci. 2003;28(1):1-5.

15. Sexena DP, Shukla SK, Kumar R. Efficacy studies of In vitro screening of antiplasmodial activity by crude extracts of Diospyrosmelanoxylem plant Res. J. Med. 2011;5:312-320.

16. Ohaeri CC, Eluwa MC. Abnornal biochemical and hematological indices in trypanosomiasis as a threat to herd production. Vet. Parasitol. 2011;177:199-202.

17. U. S. Renal Data System, (USRDS). Annual data report; atlas of endstage renal disease in the united states, national institutes of health, national institute diabetes and digestive and kidney diseases, Bethesda, MD.2002.
18. Thomas M, Tsalamandris C, MacIsaac R, Jerums G. Anaemia in diabetes: An emerging complication of microvascular disease. Curr.Diabet.Rev. 2005;1:107-126.

19. YoungNS, Maciejewski J.The path physiology of acquired aplastic anemia.New Eng.J. Med. 1997;72336-1365.

20. Nikkila EA. Plasma lipid and lipoprotein abnormalities in diabetes. In: Diabetes and Heart Diseases. Elsevier Science Publishers B.V. Amsterdam. The Netherlands.1984; 134-167.

21. Momoh J, Akoro SM, Godonu KG. Hypoglycemic and Hepatoprotective Effects of Vernoniaamygdalina(Bitter Leaf) and its effect on some biochemical parameters in alloxan-induced diabetic male albino rats.Science Journal of Biochemistry. 2014;194 (10):72377244.

\section{How to cite this article:}

Yakubu OE Nwodo OFC, Udeh SMC, Abdulrahman M., Ogri MO. Modulation of some biochemical complications arising from alloxan-induced diabetic conditions in rats treated with Senna occidentalis leaf extract. J App Biol Biotech. 2016; 4 (04): 051056. DOI: $10.7324 / J A B B .2016 .40405$ 